\title{
Roundtable on Posttraumatic Stress Disorder in the Perinatal Period
}

\author{
Penny Simkin, PT, CCE, CD(DONA) \\ Kimmelin Hull, PA, LCCE \\ Kathleen Kendall-Tackett, Ph.D., IBCLC, RLC, FAPA
}

\begin{abstract}
Editor's Note: This issue of Clinical Lactation features a roundtable discussion of psychological trauma and posttraumatic stress disorder in childbearing women. The first article provides an overview of trauma related to women's birth experiences. The second provides a summary of nondrug treatments for trauma symptoms and PTSD.
\end{abstract}

Keywords: PTSD, trauma symptoms, birth experience, trauma treatment Clinical Lactation, 2011, Vol. 2-2, 35-37

\section{Birth trauma and Posttraumatic Stress Disorder (PTSD) after Childbirth}

\section{Penny Simkin, PT, CCE, CD(DONA ${ }^{1}$ Kimmelin Hull, PA, LCCE}

According to the American Psychiatric Association (1994), trauma involves experiencing or witnessing an event in which there is actual or perceived death or serious injury, or threat to the physical integrity of self or others, and the person's response included fear, helplessness, or horror. Psychological trauma does not necessarily include actual physical damage, although it may. One's perception of the event is what defines it as traumatic or not. As it pertains to childbirth, birth trauma is in the "eye of the beholder" (Beck, 2004), and whether others would agree with the mother's perception of events is irrelevant to the diagnosis.

One national survey found that $18 \%$ of almost 1,000 new mothers (up to 18 months after childbirth) reported traumatic births, as assessed by the PTSD Symptom Scale, a highly respected diagnostic tool. Half of these women ( $9 \%$ of the sample) had high enough scores to be diagnosed with PTSD after childbirth (Declercq et al., 2008). Other smaller surveys (using women's reports as the criteria for diagnosis) have found that between $25 \%$ and $33 \%$ of women report that their births were traumatic. Of these women, between $12 \%$ and $24 \%$ developed posttraumatic stress disorder (PTSD). In other words, between 3\% and 9\% of all women surveyed developed PTSD after childbirth (Adewuya et al., 2006; Beck, 2004; Czarnocka \& Slade, 2000; Creedy et al., 2000).

As you can see, every woman who has a traumatic birth does not go on to develop the full syndrome of PTSD. If they have fewer symptoms than the three or more required for the diagnosis (see sidebar), they may be described as having PTS Effects (PTSE). Though disturbing, the women are more likely to recover spontaneously over time than those with PTSD.

The question of why some women get PTSD and others do not is intriguing and multifactorial: the propensity to develop post-birth PTSD has to do with how they felt they were treated in labor; whether they felt in control; whether they panicked or felt angry during labor; whether they dissociated; whether they suffered "mental defeat" (that is, they gave up, feeling overwhelmed, hopeless and as if they couldn't go on ) (Ayers, 2007; Czarnocka \& Slade, 2000). Another risk factor for developing birth-related PTSD is having a history of unresolved physical, sexual and/or emotional trauma from earlier in their lives. Even though unresolved previous trauma is unlikely to be healed during pregnancy, most of the other variables associated with PTSD can be prevented "through care in labor that enhances perceptions of control and support” (Czarnocka \& Slade, 2000, p. 50).

This article is an excerpt from a two-part blog post by Penny Simkin, PT, CCE, CD(DONA) to the Science Eु Sensibility blog, February 15th, 2011. Kimmelin Hull, PA, LCCE is the Science $\mathcal{E}$ Sensibility Community Manager. Click here to read the full blog post. Used with permission.

The full version of this article will be featured in the Fall, 2011 issue of the Journal of Perinatal Education.

Simkin, P., \& Hull, K. (2011, in press). Pain, suffering, and trauma in labor and prevention of subsequent posttraumatic stress disorder. The Journal of Perinatal Education, 20(3).

1 penny@pennysimkin.com 


\section{References}

Adewuya, A. O., Ologun, Y. A., \& Ibigbami, O. S. (2006). Posttraumatic stress disorder after childbirth in Nigerian women: Prevalence and risk factors. BJOG: An International Journal of Obstetrics and Gynaecology, 113(3), 284-288.

American Psychiatric Association. (1994). Diagnostic and statistical manual of mental disorders (4th Ed.). Washington, DC: Author.

Ayers, S. (2007). Thoughts and emotions during traumatic birth: A qualitative study. Birth, 34(3), 253-263.

Beck, C. T. (2004). Birth trauma: In the eye of the beholder. Nursing Research, 53(1), 28-35.

Creedy, D. K., Shochet, I. M., \& Horsfall, J. (2000). Childbirth and the development of acute trauma symptoms: Incidence and contributing factors. Birth, 27(2), 104-111.

Czarnocka, J., \& Slade, P. (2000). Prevalence and predictors of posttraumatic stress symptoms following childbirth. British Journal of Clinical Psychology, 39(1), 35-51.

Declercq, E. R., Sakala, C., Corry, M. P., \& Applebaum, S. (2008, August). New mothers speak out: National survey results highlight women's postpartum experiences. New York, NY: Childbirth Connection. Retrieved from http://www.childbirthconnection. org/pdfs/new-mothers-speak-out.pdf

\section{Diagnostic Criteria for PTSD}

According to Diagnostic and Statistical Manual IV TR (American Psychiatric Association, 2000), and the American Psychiatric Association's Practice Guidelines for PTSD (2004), a diagnosis of PTSD requires a discernible traumatic event, one that victims perceive as life-threatening for themselves or a loved one. The victim must have responded with fear, helplessness or horror. In addition, there must be symptoms in each of three clusters: 1) re-experiencing, 2) avoidance/ numbing, and 3) hyperarousal.

- Re-experiencing includes frequent intrusive thoughts of the event via nightmares or repetitive daytime thoughts.

- Avoidance includes numbing, avoiding situations that remind them of the traumatic event, and even amnesia about all or part of the event.

- Hyperarousal includes persistent jumpiness, sleep disturbances, poor concentration, and chronic activation of the sympathetic nervous system. Depression, another manifestation of chronic hyperarousal, is a common co-occurring symptom that must be addressed as well.

American Psychiatric Association. (2000) Diagnostic and statistical manual of mental disorders, 4th Ed., Text Revision. Washington DC: Author.

American Psychiatric Association. (2004). Practice guidelines for the treatment of patients with acute stress disorder and posttraumatic stress disorder. Washington, DC: Author.

Kathleen Kendall-Tackett, Ph.D., IBCLC, RLC, FAPA

\section{Non-Drug Treatments of Trauma Symptoms and Posttraumatic Stress Disorder (PTSD)}

\author{
Kathleen Kendall-Tackett, Ph.D., IBCLC ${ }^{2}$
}

Traumatic events are relatively common in the lives of childbearing women. According to the U.S. National Center for PTSD (www.ncptsd.va.gov), 51\% of American women have been exposed to at least one trauma-producing event in their lifetimes, and 6\% have been exposed to four or more. As Simkin and Hull described above, exposure to traumatic events does not automatically lead to a diagnosis of PTSD (American Psychiatric Association, 2004). Women are twice as likely as men to meet full diagnostic criteria during their lifetimes (10.4\% of women vs. $5 \%$ of men). Even when women don't meet full criteria, up to one third can have symptoms of trauma that impair their physical and mental health (Kendall-Tackett, 2005).

The National Center for PTSD (www.ncptsd.va.gov) lists the most common traumatic experiences for women as rape, sexual molestation, physical attack, being threatened with a weapon, and childhood physical abuse. Trauma in the perinatal period can also be caused by previous pregnancy loss, preterm birth, neonatal death, or a frightening or life-threatening birth experience (Kendall-Tackett, 2005; 2010). [Read more about trauma associated with perinatal events.]

\section{Treatments for PTSD and Trauma Symptoms}

Comprehensive trauma treatment involves a wide range of activities including patient education, peer support, and trauma-focused psychotherapy-all of which are compatible with breastfeeding. There are also medications that can be added to the treatment regimen. While medications are useful adjuncts, they are not the primary treatments for PTSD and are described in an article entitled, Medications for Trauma Symptoms and PTSD in Pregnant and Breastfeeding Women [Read more.]. Non-drug treatments are described below.

\section{Psychoeducation and Peer Counseling}

The role of both psychoeducation and peercounseling is to help clients understand their experiences and their reactions in the wake of traumatic events. Clients are given information on how to avoid secondary exposure to the event, how to reduce stress responses, and where to go if they need ongoing support. By understanding that their reactions are predictable after traumatic

2 kkendallt@aol.com 
events, clients are less likely to blame themselves and are more likely to comply with treatment.

\section{Trauma-focused Psychotherapy}

The two most effective types of psychotherapy for PTSD and trauma symptoms are cognitive-behavioral therapy (CBT) and EMDR. As non-drug treatments, they are both safe for pregnancy and breastfeeding.

Cognitive-Behavioral Therapy. The focus of cognitive therapy, in general, is to help clients identify faulty ways of thinking that increase the risk of depression, and challenging those beliefs with more accurate cognitions. In trauma treatment, this same approach targets distortions in clients' threat-appraisal processes, and helps to desensitize them to trauma-related triggers (i.e., events that remind them of the traumatic event; American Psychiatric Association, 2004). CBT is a highly effective approach and variants to this approach include exposure therapy and stress-inoculation training (Friedman, 2001).

Eye Movement Desensitization and Reprocessing (EMDR). In EMDR the client is instructed to focus on the image, negative thought, and body sensations while simultaneously moving his/her eyes back and forth following the therapist's fingers as they briefly move across his/her field of vision. Eye movements are the most commonly used external stimulus. But therapists often use auditory tones, tapping, or other types of tactile stimulation. Clients can simply think about their traumatic experiences, rather than having to verbalize them. This technique has proven highly effective in reducing symptoms after a few sessions, and has been approved by the American Psychiatric Association and the U.S. Veterans Administration for treating PTSD. Certified practitioners of EMDR are available in many parts of the world. An international list of practitioners can be found at the EMDR Institute (www.emdr.com) or the EMDR International Association (www.emdria. com).

\section{Summary}

Trauma symptoms and PTSD are both treatable conditions, with a wide array of treatment options available. Non-drug modalities are frontline treatments for women with trauma symptoms and PTSD. All of these modalities are safe for pregnant and breastfeeding women. [To learn more about other steps women can take to overcome difficult birth experiences, click here.]. A printable version of this article is available here.

\section{References}

American Psychiatric Association. (2000) Diagnostic and statistical manual of mental disorders, 4th Ed., Text Revision. Washington DC: Author.

American Psychiatric Association. (2004). Practice guidelines for the treatment of patients with acute stress disorder and posttraumatic stress disorder. Washington, DC: Author.

Friedman, M.J. (2001). Posttraumatic stress disorder: The latest assessment and treatment strategies. Kansas City, MO: Compact Clinicals.

Kendall-Tackett, K.A. (2005). Handbook of women, stress and trauma. New York: Taylor \& Francis.

Kendall-Tackett, K.A. (2010). Depression in new mothers: Causes, consequences and treatment options, 2nd Edition. London: Routledge.

\section{Case Study: Difficulties in a Previous Lactation Experience Can Influence Subsequent Breastfeeding Experiences}

Gail Peterson, ARNP, IBCLC, RLC ${ }^{1}$

Sharon was a 29-year-old first-time mother with an uncomplicated pregnancy. She delivered in a hospital vaginally, a term infant girl "Anne" with Apgar scores of 8 and 9 . No breastfeeding concerns were identified with Sharon and Anne in the hospital.

On day six, Anne was referred by the pediatrician to see the Mary, an ARNP, IBCLC, for latch difficulties and infant weight loss. At the time Sharon was identified as

1 gail.peterson@providence.org having delayed lactogenesis causing infant weight loss. Anne was 10 percent below the birth weight of $7 \mathrm{lb} .12$ ounces. Sharon was taught appropriate latch and was shown how to supplement using the tube-and-syringe method. Anne did not suckle; she tended to chew. Sharon was shown how to double-pump and a hospitalgrade rental pump was secured.

Anne was seen two days later with a 5-ounce weight gain. Sharon was supplementing at the breast with 1 ounce of 